\title{
Silver Nanoparticles as a Potent Fungicide for Citrus Phytopathogenic Fungi
}

\begin{abstract}
Pathogenic Fungal infections have tremendous harmful effects on human health and economy. Citrus fruit crop has an immense economic, social and Health impact on human all over the world. Citrus fruits are attacked by a number of pathogens from bloom to harvesting stage and subsequently by post-harvest pathogens that affect fruit yield and considerably deteriorate the fruit quality. In the present work, survey was conducted during 2014 and 2015 to evaluate the incidence of citrus leave spots and fruit decay in some orchards in Menofiea and Beheira governorates, Egypt. Three different fungi were isolated from samples of citrus. Alternaria alternata was the most abundant fungal pathogen isolated from citrus leaf and fruit spots followed by Alternaria citri and Penicillium digitatum. Silver nanoparticles were tested as a potent fungicide that may replace the dangerous cytotoxic fungicides. Silver nanoparticles were synthesized with 10 $\pm 5 \mathrm{~nm}$ average diameter size. In vitro assay was carried out on Potato Dextrose Agar (PDA) media treated with 50,100 and $150 \mathrm{ppm}$ of silver nanoparticles in addition to two control traditional fungicides products, namely Iprodione and Difenoconazole at $150 \mathrm{ppm}$ concentrations. Results revealed that Silver nanoparticle, $150 \mathrm{ppm}$, showed potent antifungal activity against the isolated fungi that will open the gate of new generation of less harmful fungicides replacing the cytotoxic dangerous currently used fungicides.
\end{abstract}

Keywords: Silver nanoparticle; Citrus; Penicillium; Alternaria; Fungi

Research Article
Volume 3 Issue 5 - 2016
Gehan AM Abdelmalek ${ }^{1}$ and Taher A
Salaheldin' ${ }^{2 *}$
${ }^{1}$ Plant Pathology Research Institute, Agriculture Research
Center, Egypt
${ }^{2}$ Nanotechnology and Advanced Materials Central Lab,
Agriculture Research Center, Egypt
*Corresponding author: Taher A Salah Eldin,
Nanotechnology \& Advanced Materials Central Lab,
Agriculture Research Center. 9 Elgamaa St., P.O. 588orman,
Giza, Egypt, Tel: +201001030534; Fax: +20235713250;
Email: t1salah@hotmail.com, tahersalah@arc.sci.eg
Received: April 07, 2016 | Published: May 05, 2016

Abbreviations: PDA: Potato Dextrose Agar; ICR: Internal Core Rot; SER: Stem-End Rot; AgNPs: Silver Nanoparticles; ICP: Inductivity Coupled Plasma; GRAS: Generally Regarded as Safe

\section{Introduction}

Citrus fruit crop has a tremendous economic, social and Health impact on human all over the world. Citrus fruit belongs to genus Citrus and family Rutaceae, include oranges, lemons, limes and grapefruits and widely used as edible fruits. It is cultivated throughout the tropical and temperate regions of the world such as Egypt. Oranges (sweet, mandarin and sour) are the most abundant as fresh fruit and they contribute to roughly 80 percent of the world's Citrus fruit production [1]. Egypt annually produces about 3 million tons of Citrus fruits, of which orange is leading in term of production, so Citrus occupies a place of considerable importance in the fruit economy of Egypt. Citrus fruits are attacked by a number of pathogens from bloom to harvesting stage and subsequently by post-harvest pathogens that affect fruit yield and considerably deteriorate the fruit quality these are Alternaria citri, Botryodiblodia theobromae, Fusarium sp., Penicillium digitatum and Penicillium italicum [2,3]. The commercial loss from decay could reach $30-50 \%$ in some susceptible citrus cultivars. Citrus black rot caused by Alternaria spp. is significant post-harvest problem. Alternaria is found on citrus fruits as SER (stem-end rot) and ICR (internal core rot) or black rot. Alternaria citri Ellis \& Pierce or A. alternata Fr. (Keissler) cause these rots. Alternaria citri is widely distributed in citrus-growing areas in Egypt [4]. Nanotechnology has emerged as a tool to explore the darkest avenues of Science and technology research and promises a pool of research and opportunities in areas of medicine and healthcare, biotechnology, materials and manufacturing, energy, etc.

Nanotechnology refers to a nanoscale technology, which has promising applications in day-to-day life [5]. Nanoscale science and nanotechnologies are envisioned to have the potential to revolutionize agriculture and food systems [6] and has given birth to the new era of Agronanotechnology. The antimicrobial properties of silver have been documented since 1000 B.C., when silver vessels were used to preserve water, but its applications in the field of agriculture have gained momentum very recently. Commendable efforts have been made to explore antimicrobial property of silver nanoparticles (AgNPs) against human pathogens, but insignificant research has been done to study its effects against overwhelming phytopathogens [7]. Numerous studies have established the fungicidal effects of nanosilver against several phytopathogenic fungi [8], but the fungicidal mechanism of this compound has not been clearly elucidated. There are volumes of literature stating the in vitro activity of AgNPs against several fungi, but very few researchers have paid attention to the application of AgNPs as antifungal compounds in controlling plant diseases in the fields and in turn promote the overall plant growth. Application of AgNPs in soil and as seed/ seedling coatings may not only control the phytopathogens, but also stimulate plant growth by several known and unknown mechanisms.

This study represents a real field study on some orchards in two different Egyptian governorates namely Menofiea and Beheira to find out the problems related to quality degradation and cosmetic issues of citrus fruit. The study is based on Isolation, identification and prevention of the fungal pathogens that are involved in citrus 
fruit's quality degradation and cosmetic problems that makes the fruit unacceptable in international markets. Silver nanoparticles were applied as a rout for reduction of Citrus fruit's fungal growth that may replaces the use of traditional cytotoxic fungicides. That may help in future to find out solution for the problems to prevent the citrus fruit quality which will be very helpful to maintain the export quality of Egypt citrus fruits and will improve the economy of the country as well.

\section{Materials and Methods}

\section{Synthesis of silver nanoparticles}

Spherical silver nanoparticles (AgNPs) were synthesized using chemical reduction method described by Van Donge with little modification. $344 \mathrm{ml}$ of $4.65 \mathrm{mM}$ silver nitrate ( $\geq 99.0 \%$, SigmaAldrich, Germany) solution was stirred at room temperature for 15 min. A mixture of $2 \mathrm{M}$ trisodium citrate dehydrate $(99.0 \%$, Fluka, Germany) and $0.504 \mathrm{~g}$ of polyvinyl pyrrolidone (PVP40, Sigma-Aldrich, USA) was dissolved in $48 \mathrm{~mL}$ deionized water, stirred for $15 \mathrm{~min}$ and then added to the prepared AgNO3 solution. $8 \mathrm{~mL}$ of freshly prepared cold aqueous solution 1M Sodium tetrahydridoborate (99.99\% trace metals basis, Fluka, Germany) was quickly added to the formed solution with continuous stirring for $30 \mathrm{~min}$, the reduction reaction occurs with formation of clear yellowish brown silver nanoparticles solution. In order to examine the existence of non-reacted free Ag+ ions in the colloidal solution of silver nanoparticles, sodium chloride salt solution was added to the synthesized Ag nanoparticles. The solution turned turbid if in presence of non-reacted Ag free ions. Formation of totally clear golden yellow solution reveals that all the free Ag ions were reacted forming Ag nanoparticles [9,10].

\section{Characterization of silver nanoparticles}

The synthesized silver nanoparticles were processed for physicochemical characterization techniques. Spectra absorption were recorded using a double beam UV-Vis spectrophotometer (Cary 5000, Varian, Australia). The morphology of AgNPs and their particle sizes were imaged using High Resolution Transmission electron Microscope (HRTEM, Tecnai, G20, FEI, Netherlands), operating at an accelerating voltage of $200 \mathrm{kV}$. A drop from a dilute silver nanoparticles solution was deposited on carbon coatedcopper grid and left to evaporate at room temperature forming a monolayer. Particle size distribution were measured by zeta sizer (Nano ZS, zeta sizer, Malvern, UK) based on the dynamic light scattering technique. X- ray Diffraction (XRD) technique was used for phase analysis. X-ray diffraction patterns were recorded in the scanning mode on XDR instrument ( X'pert PRO, PANanalytical, Netherlands) operated at $40 \mathrm{kV}$ and a current of $30 \mathrm{~mA}$ with $\mathrm{Cu} \mathrm{K}$ radiation $(=1.54 \mathrm{~A})$. The diffraction intensities were compared with the standard ICCD library. PDF4 software gave the information about the crystal structure of the Ag NPs. Silver concentrations were measured by Inductivity Coupled Plasma (ICP) instrument (PerkinElmer ICP-OES: Optima 2000, Germany). The preparation and characterization of silver nanoparticles were conducted at the Nanotechnology and Advanced Materials Central Lab, Agriculture Research Center, Giza, Egypt.

\section{Disease survey and samples collection}

Survey was conducted during two successive seasons, 2014 and 2015, to examine the incidence of citrus leave spots and fruit decay from citrus producing orchards in two different Egyptian governorates namely Menofiea and Beheira governorates. Onehundred citrus trees were randomize chosen in each of these localities for the intended study's investigations. Then samples were brought for lab identification of pathogens causing quality degradation of citrus fruit. Diseased Citrus Fruits were processed for surface sterilization by washing under running tap water and with distilled water. Surface sterilization was done with ethanol of $85 \%$ concentration for 2 minutes. Then the surface residue ethanol was washed away several times [11].

\section{Pathogens isolation}

Diseased samples were collected and cleaned in tap water, blotted dry and dissected into small pieces (3-5 mm) containing both necrotic and healthy tissues then immersed in $0.5 \%$ sodium hypochlorit for $2 \mathrm{~min}$, rinsed in sterilized distilled water, blotted dry and incubated on Potato Dextrose Agar (PDA) medium at

$27 \pm 1^{\circ} \mathrm{C}$. After 5 days, fungi were purified by using hyphal tip technique [12]. Purified fungi were transferred to Potato Dextrose Agar (PDA) and genera of isolates were then identified on the basis of morphological characteristics according to Barnett and Hunter [13] and further authenticated by the Mycology and Plant Diseases Survey Department, Plant Disease Research Institute, Agriculture Research Center, Giza, Egypt.

\section{Pathogenicity test}

Fruit decay: Healthy fruits of mature "Washington" Navel orange obtained from the selected orchards were surface sterilized by $1 \%$ sodium hypochlorite solution for $3 \mathrm{~min}$, then washed by rinsing these fruits in sterilized distilled water for three times and dried with sterilized filter paper according to [2]. Inoculation procedures were performed under aseptic conditions by inserting $6 \mathrm{~mm}$ agar disc of the tested fungus into holes $(6 \mathrm{~mm}$ diameter and $4 \mathrm{~mm}$ depth) made in both "stem-end and blossom-end" of fruit using a sterilized cork borer. Agar discs of each tested fungi i.e. Alternaria citri, Penicillium digitatum and Alternaria alternata (about $5 \mathrm{~mm}$ diameter) were taken from the margin of 10 days old PDA-cultures of the isolated fungi. After inoculation, the holes were plugged with the removed pieces of the peel. Three replicates, each of five fruits, were used for each tested fungi and control treatment was carried out by sterilized water only. The inoculated fruits were placed into carton boxes and then incubated at $22 \pm 2$ ${ }^{\circ} \mathrm{C}$ and $65 \%$ relative humidity. Infected fruits were recorded after 7 days from inoculation. The disease incidence of blossom and stem end rot was calculated as percentage of infected navel orange fruit in relation to the total number of fruits in each replicate according to the following formula:

$$
\text { Infection }(\%)=\frac{\text { Number of rotted fruits }}{\text { Total number of tested fruits }} X 100
$$

Leave spots: Five mm agar disc of the isolated fungi i.e. Alternaria citri, Penicillium digitatum and Alternaria alternata were taken from the margin of 10 days old PDA-cultures used to inoculate leaves on detached current year shoots of citrus grown in water. For this purpose, sporulating mycelial disk $(5 \mathrm{~mm})$ was placed on the upper side of a young leaf which had been washed, sterilized with ethanol $70 \%$ and wounded by scratching the epidermis. Inoculated leaves (on shoots) covered with plastic bags supplemented with moister cotton to maintain high humidity and assessed for disease symptoms after 10 days by using percentage of infected surfaces according to Francis MI et al. [14]. 


$$
\text { Percentage of infected surfaces }=\frac{\text { Infected area of leaf }}{\text { Total area of leaf }} X 100
$$

\section{Antifungal activity of silver nanoparticles}

The synthesized Silver nanoparticles (AgNPs) were tested for its potent antifungal activity against the isolated Citrus fruits fungal pathogens; Alternaria alternata, Penicillium digitatum and Alternaria citri. The fungal pathogens were grown on Potato

Dextrose Agar (PDA) and incubated at $28 \pm 2{ }^{\circ} \mathrm{C}$ for 7 day. In vitro assay was carried out on PDA treated with 50,100 and 150 ppm of silver nanoparticles in addition to two control traditional fungicides products, namely Iprodione and Difenoconazole at 150 ppm concentrations. The selected treatment doses were poured into the media before plating into each $90 \times 15 \mathrm{~mm}$ Petri dish and incubated at room temperature. After $48 \mathrm{hr}$ of incubation, an agar plug of $5 \mathrm{~mm}$ diameter containing fungi was inoculated simultaneously at the center of each Petri dish and incubated at $28 \pm 2 \circ \mathrm{C}$. After 2 weeks of incubation, inhibition zones were measured. The test was repeated twice and each treatment replicated three times. The inhibition rate (\%) was calculated by using the following formula [15].

$$
\text { Inhibition rate }(\%)=\frac{R-r}{R} X 100
$$

Where $\mathrm{R}$ is radial growth of fungi in control plate and $\mathrm{r}$ is the

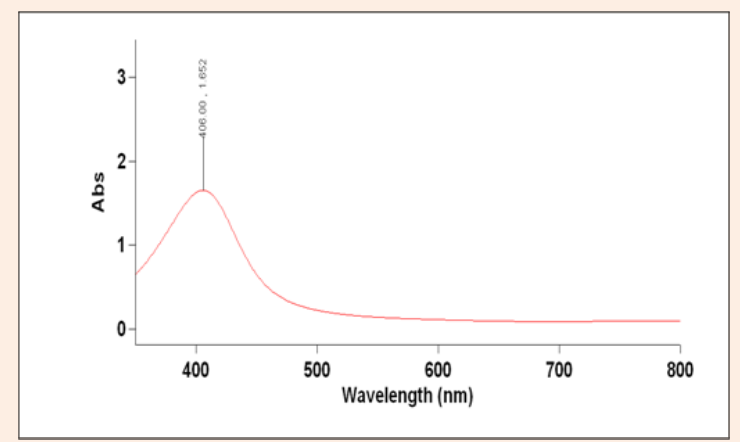

Figure 1a: UV-Vis spectrum for silver nanoparticles showing peak AgNPs absorption at wavelength $400.00 \mathrm{~nm}$.

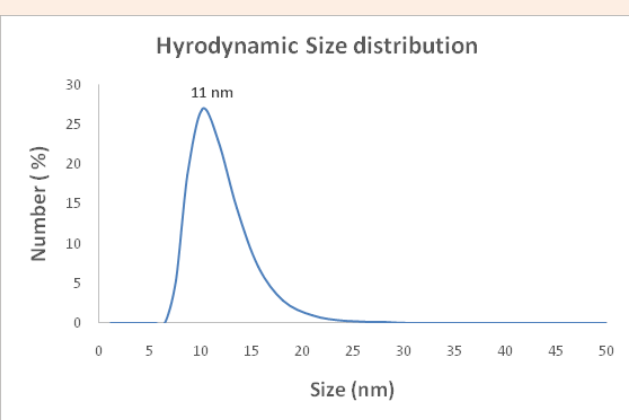

Figure 1c: Particle size distribution of AgNPs with average hydrodynamic size distribution of $11 \mathrm{~nm}$. radial growth of fungi in silver nanoparticle treated plates.

\section{Statistical analysis}

Data were statically analysed using analysis of variance and means were compared using L.S.D. test at $5 \%$ probability as described by Gomez \& Gomez [16].

\section{Results and Discussion}

\section{Characterization of silver nanoparticles}

Figure 1 summarizes the results of AgNPs characterization which confirm the success of synthesis of spherical silver nanoparticles with accepted size distribution. UV-Visible absorption spectrophotometer measurements showed absorption peak at $406 \mathrm{~nm}$ which is the characteristic plasmatic absorption band corresponding to the spherical silver nanoparticles (Figure 1a). Transmission electron microscope image showed silver nanoparticles was spherical with average size rang $10 \pm$ $5 \mathrm{~nm}$ in diameter (Figure 1b). Particle size distribution analysis showed main hydrodynamic particle size to be $11 \mathrm{~nm}$ diameter as illustrated in Figure 1c. Structural and phase characterization performed using XRD analysis and the typical XRD pattern for silver nanoparticles (Figure $1 \mathrm{~d}$ ). The characteristic peaks located at $2 \theta=38.91^{\circ}, 44.39^{\circ}, 64.58^{\circ}$ and $77.58^{\circ}$ respectively. The result indicates that the sample is composed of crystalline silver nanoparticles with cubic unit cell using card number: 04-0035625.

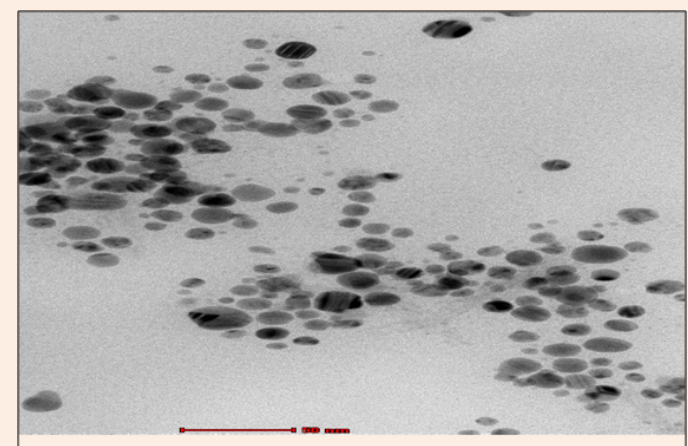

Figure 1b: HRTEM image of AgNPs showing spherical with average size $10 \pm 5 \mathrm{~nm}$.

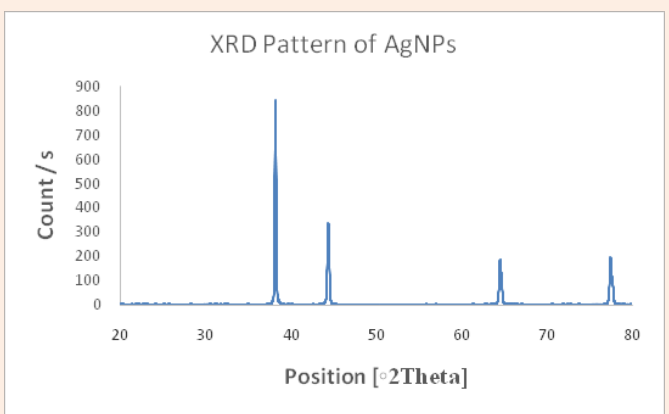

Figure 1d: XRD pattern analysis indicating the formation of AgNPs with cubic unit crystal, Card No: 04-003-5625

Figure 1: Physiochemical characterization of the as prepared AgNPs 


\section{Field survey and disease incidence}

Many orchards of citrus crop from three different locations in each of Beheira and Menofeya governorates were surveyed during 2014 and 2015 seasons. Data illustrated in Table 1 showed that, typical symptoms of leaf and fruit spots of citrus were observed in all examined governorates. Disease incidence was found to be different from one location to another. In 2014 season disease incidence of naturally infection of leave spots ranged from $32 \%$ in Ashmon -Menofeya to $49 \%$ in Rasaheed - Beheira. Similar results were obtained in 2015 season in the same locations. In general, all orchards in Beheira governorate recorded the highest percent of disease incidence as compared with Menofeya, meanwhile disease incidence of naturally infection of fruit decay ranged from $26 \%$ in Ashmon -Menofeya to 35 \% in Rasaheed - Beheira. Similar results were obtained in 2015 season in the same locations. In general, all orchards in Beheira governorate recorded the highest percent of disease incidence as compared with Menofeya. Differences between the inspected locations may ascribed to different reasons, such as age of the orchard in the same area, suitability of agricultural practices which were always performed, duration of the fruits presence on the trees during year and types and efficiency of the sanitary methods and control means protectant or curative treatments against diseases and insects [17].

The most severe postharvest fungal diseases of citrus fruit are green and blue moulds caused by Penicillium digitatum (Pers.:Fr.) Sacc. and Penicillium italicum Wehmer, respectively [18]. Blue mould is important on fruit kept under cold storage, whereas green mould may cause $60-80 \%$ of decay under ambient conditions [19], although numerous factors related to the fruit itself, the pathogen and the postharvest environment can influence incidence and severity [20]. Alternaria citri is widely distributed in citrus-growing areas. In Navel oranges, fungal conidia may be located at the stylar end. Alternaria black rot of citrus may occur in the field before harvest. The disease is a common problem in Mediterranean climates due to cool, moist winters and hot dry summers [21]. In one of the first descriptions of Alternaria rot of citrus, the causal agent was identified as Alternaria citri [22] (Figure 2).

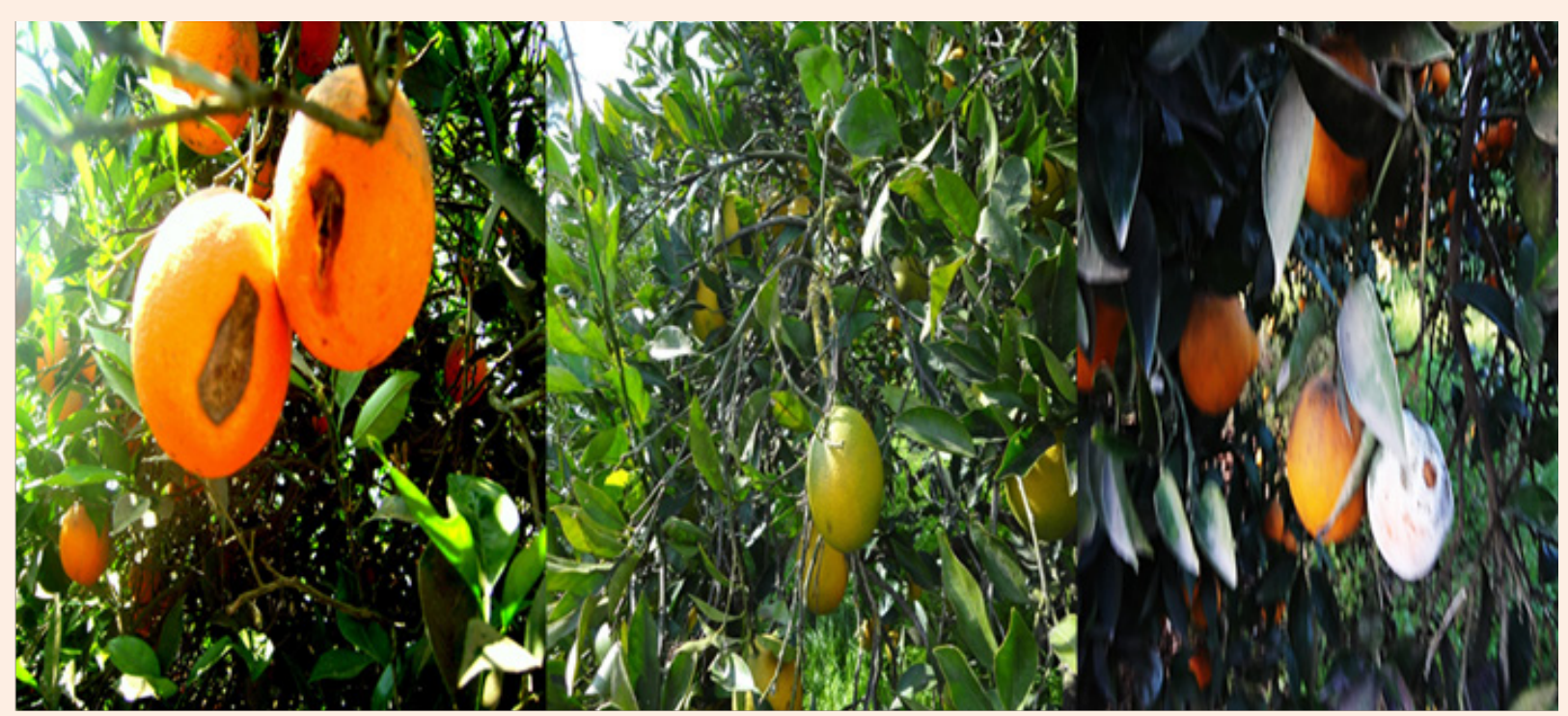

Figure 2: field images for fungal infections of citrus groves illustrating the sporadic infection

Table 1: Field survey and Disease incidence of citrus leave spots and fruit decay in three different locations in each of Menofeya and Beheira governorate during 2014 and 2015 seasons.

\begin{tabular}{|c|c|c|c|c|c|}
\hline \multirow{3}{*}{\multicolumn{2}{|c|}{ Location }} & \multicolumn{4}{|c|}{ Disease Incidence (\%) } \\
\hline & & \multicolumn{2}{|c|}{2014} & \multicolumn{2}{|c|}{2015} \\
\hline & & Leave Spots & Fruit Decay & Leave Spots & Fruit Decay \\
\hline \multirow{3}{*}{ Menofeya } & Quesna & 39 & 31 & 41 & 35 \\
\hline & Ashmon & 32 & 26 & 36 & 31 \\
\hline & Al-Shohda & 34 & 28 & 38 & 28 \\
\hline \multirow{3}{*}{ Beheira } & Abo-Homes & 40 & 33 & 42 & 25 \\
\hline & Kafer aldwar & 43 & 30 & 45 & 21 \\
\hline & Rasaheed & 49 & 35 & 51 & 27 \\
\hline L.S.D. ${ }_{0.05}$ & & 3.2 & 2.7 & 2.9 & 2.6 \\
\hline
\end{tabular}




\section{Fungal isolation and frequency}

Three different fungi were isolated from samples of citrus collected from orchards in two studied governorates as illustrated in table (Table 2). Alternaria alternata was the most abundant fungal genus isolated from citrus leaf and fruit spots record 40.5\% total frequency followed by Alternaria citri and Penicillium digtatum (being 30.3 and 29.3\%, respectively). The highest total frequency of isolated fungi was detected from samples brought from Beheira being 57.1\%. Meanwhile, in Menofeya governorate reported the lowest fungal frequency being $42.9 \%$. Green mould rot occur in all citrus growing areas and often constitute the predominant type of decay [2]. Citrus rot caused by Alternaria spp. is significant post harvest problem. The causal agent of black rot was originally identified as A. citri by Ellis and Pierce [23]. The genus Alternaria circumscribes considerable morphological diversity and citrus black rot may be caused by more than one morphospecies in addition to A. citri [23-25]. Alternaria black rot of citrus may occur in the field before harvest. It infected most commonly citrus, navel oranges (Citrus sinensis (L.) Osbeck) in the field and in the storage. The disease is a common problem in Mediterranean climates due to cool, moist winters and hot dries [23].

Table 2: Frequency of isolated fungi in Menofeya and Beharea governorate during seasons of 2014-2015.

\begin{tabular}{|c|c|c|c|c|c|c|}
\hline \multirow{2}{*}{\multicolumn{2}{|c|}{ Location }} & \multicolumn{5}{|c|}{ Frequency of isolated fungi (\%) } \\
\hline & & \multirow{2}{*}{$\begin{array}{c}\begin{array}{c}\text { Alternaria } \\
\text { alternate }\end{array} \\
5.5\end{array}$} & \multirow{2}{*}{$\begin{array}{c}\begin{array}{c}\text { Alternaria } \\
\text { citri }\end{array} \\
4.4 \\
\end{array}$} & \multirow{2}{*}{$\begin{array}{c}\begin{array}{c}\text { Penicillium } \\
\text { digtatum }\end{array} \\
3.7 \\
\end{array}$} & \multicolumn{2}{|c|}{ Total } \\
\hline \multirow{3}{*}{ Menofeya } & Quesna & & & & 13.7 & \multirow{3}{*}{42.9} \\
\hline & Ashmon & 6.3 & 4.6 & 3.9 & 14.8 & \\
\hline & Al-Shohda & 6 & 3.8 & 4.7 & 14.5 & \\
\hline \multirow{3}{*}{ Beheira } & Abo-Homes & 7.7 & 5.5 & 5.2 & 18.5 & \multirow{3}{*}{57.1} \\
\hline & Kafer aldwar & 7.3 & 5.8 & 5.8 & 18.8 & \\
\hline & Rasaheed & 7.6 & 6.2 & 6 & 19.8 & \\
\hline Total & & 40.5 & 30.3 & 29.3 & 100 & \\
\hline
\end{tabular}

\section{Pathogenicity test}

All the tested fungi were pathogenic, with varied degree to citrus leaves and showed also different level of disease symptoms on fruits (Table 3 \& Figure 3). Alternaria alternata and Alternaria citri caused the highest leaf spots severity being 55.8 and $30.9 \%$ respectively. Meanwhile, Penicillium digtatum was not pathogen as leave spots. In the contrary, Penicillium digtatum was the most pathogenic fungi on fruits recorded $86.7 \%$ disease incidence followed by Alternaria alternata and Alternaria citri being 53.3 and $46.7 \%$ respectively. Alternaria is found on citrus fruits as SER (stem-end rot) and ICR (internal core rot) or black rot. Alternaria citri Ellis \& Pierce or A. alternata Fr. (Keissler) cause these rots. Fungus survives on infected twigs, stems and leaves from one year to another [4].

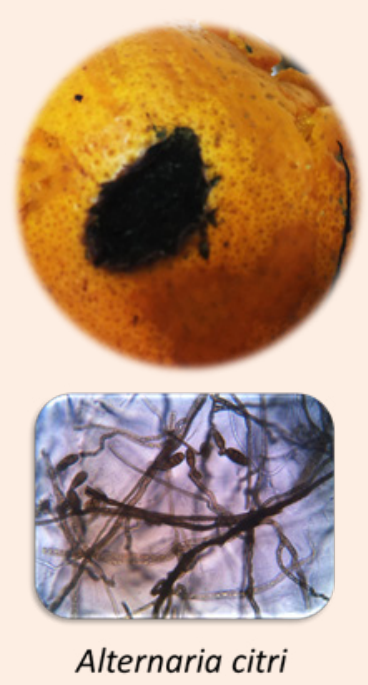

Alternaria citri

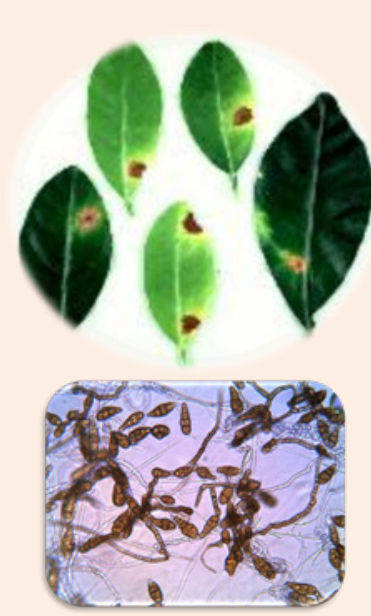

Alternaria alternate

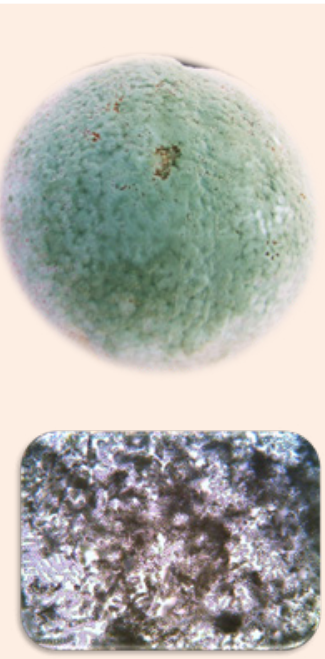

Penicillium digtatum

Figure 3: Visual and Microscopic identification of the sporadic fungal infections of the citrus fruits and leaves. 
Table 3: Pathogenic capabilities of the isolated fungi on citrus leaves and fruits.

\begin{tabular}{|c|c|c|}
\hline Pathogen & Leave Spots (Infected surfaces, \%) & Fruit Decay (Infection, \%) \\
\hline Alternaria alternata & 55.8 & 53.3 \\
\hline Alternaria citri & 30.9 & 46.7 \\
\hline Penicillium digitatum & 0 & 86.7 \\
\hline L.S.D & 3.9 & 2.6 \\
\hline
\end{tabular}

\section{Antifungal activity of silver nanoparticles}

The synthesized Silver nanoparticles (AgNPs) were tested for its potent antifungal activity against the isolated Citrus fruits fungal pathogens; Alternaria alternata, Penicillium digitatum and Alternaria citri. The fungal pathogens were grown on potato dextrose agar (PDA) and incubated at $28 \pm 2{ }^{\circ} \mathrm{C}$ for 7 day. In vitro assay was carried out on PDA treated with 50, 100 and 150 ppm of silver nanoparticles in addition to two control traditional fungicides products, namely Iprodione and Difenoconazole at $150 \mathrm{ppm}$ concentrations. The growth of Alternaria alternata, Penicillium digitatum and Alternaria citri, was greatly suppressed by silver nanoparticles in a concentration dependent way and the maximum inhibitory effect was recorded concentration of $150 \mathrm{ppm}$, indicating promising antifungal activity of the synthesized silver nanoparticles against the test fungi compared to the traditional used reference fungicide, Iprodione and Difenoconazole at concentration of $150 \mathrm{ppm}$. Table 4 \& Figure 4 represent the detailed date obtained from the in vitro excrement. Where, the \% rate of inhibition was found to be about $83.88 \%$ in Alternaria alternata at the maximum tested concentration (150 ppm), 78.88 and $81.11 \%$ in Penicillium digitatum and Alternaria citri., respectively. In the other hand the inhibition rate $\%$ of two reference fungicides as Iprodione and Difenoconazole at 150 ppm concentrations on Alternaria alternate was $93.3 \%$ and 91.2 $\%$ respectively, on Penicillium digitatum, was $96.1 \%$ and $94.2 \%$ respectively, on Alternaria citri was $94.2 \%$ and $93.2 \%$ respectively. Thus, the obtained results of the present study clearly revealed that the as prepared silver nanoparticles have portent antifungal activity against the tested fungi that may replace the traditional cytotoxic harmful fungicides.

Traditionally, control is performed with synthetic fungicides. However, issues associated with their use, such as risks for human and environmental health, pathogen resistance, costs of registration and re-registration of active ingredients, etc., have motivated the search for new and safer alternatives [26]. In a previous study, several salts included in the Generally Regarded as Safe (GRAS) category were tested in vitro and in vivo against Penicillium rots of citrus fruit [27,28]. Mounting evidences suggest that silver nanoparticles act as promising antimicrobial agents and may emerge as an alternative to conventional antibiotics. Similarly, the present study also supports the above fact. Interestingly, silver nanoparticles exhibited potent antifungal activity against all the tested pathogens even at low concentration $(50 \mathrm{ppm})$. At this juncture, it is of paramount important to understand the mode of action of silver nanoparticles. Though it is not well understood, some hypotheses arise to validate the antifungal activity of silver nanoparticles. Several studies have showed that silver nanoparticles may kill fungal spores by destructing the membrane integrity [29]. In other studies, it has been indicated that silver nanoparticles may interact with phosphorus and sulphur containing compounds and their interaction may cause damage to DNA and proteins resulting in cell death. From this study, it is evident that silver nanoparticles may have important applications in the agricultural sector and could be used as an effective antifungal agent against the harmful plant pathogens.

Table 4: Inhibition rate (\%) of silver nanoparticles against the isolated fungal pathogens compared to the reference fungicide controls, Iprodione and Difenoconazole.

\begin{tabular}{|c|c|c|c|c|c|c|}
\hline \multirow{3}{*}{ Fungi } & \multicolumn{6}{|c|}{ Inhibition Rate (\%) } \\
\hline & \multicolumn{3}{|c|}{ Sliver Nanoparticles } & \multirow{2}{*}{\begin{tabular}{|c|} 
Iprodione \\
$150 \mathrm{ppm}$
\end{tabular}} & \multirow{2}{*}{$\begin{array}{c}\text { Difenoconazole } \\
150 \mathrm{ppm}\end{array}$} & \multirow[t]{2}{*}{ L.S.D. ${ }_{0.0}$} \\
\hline & 50 ppm & $100 \mathrm{ppm}$ & $150 \mathrm{ppm}$ & & & \\
\hline Alternaria alternata & $62.22 \pm 21$ & $73.33 \pm 3.3$ & $83.33 \pm 4.8$ & $93.3 \pm 2.4$ & $91.2 \pm 4.1$ & 3.8 \\
\hline Penicillium digitatum & $55.55 \pm 3.4$ & $66.66 \pm 2.7$ & $78.88 \pm 2.7$ & $96.1 \pm 4.6$ & $94.2 \pm 5.3$ & 4.1 \\
\hline Alternaria citri & $57.55 \pm 1.6$ & $68.88 \pm 4.1$ & $81.11 \pm 3.8$ & $94.2 \pm 3.9$ & $93.2 \pm 4.4$ & 3.9 \\
\hline
\end{tabular}




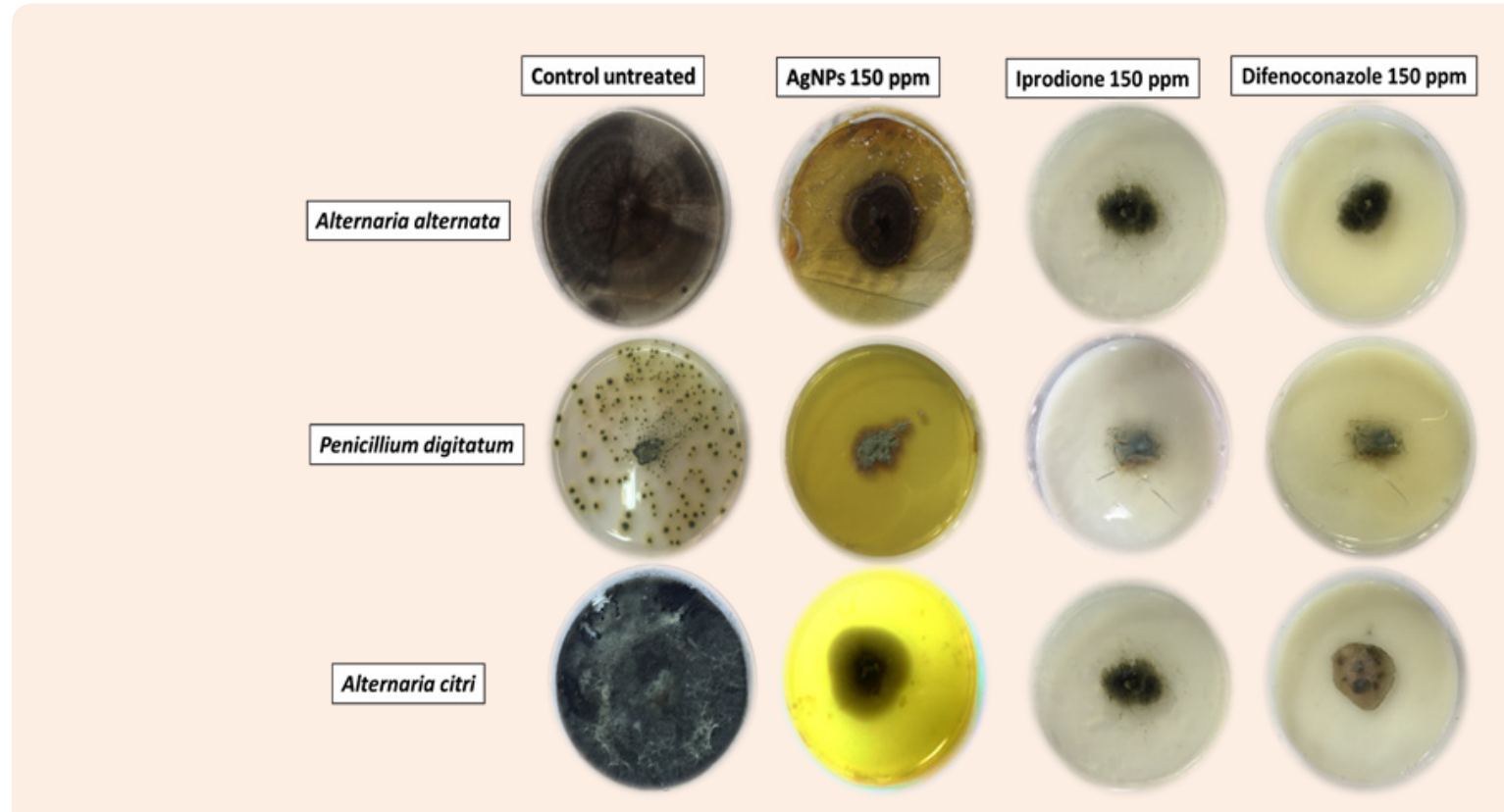

Figure 4: Isolated fungal pathogen culture on PDA media and Inhibation rate $\%$ of the tested fungicides (silver nanoparticles, Iprodione and Difenoconazole).

\section{Conclusion}

In the present study, silver nanoparticles with greater stability were synthesized using simple, low cost and eco-friendly green chemistry approach. This single step procedure is highly suitable for large scale production as it is very rapid and eliminates the elaborate processes employed in the other bio-based protocols. Interestingly, silver nanoparticles exhibited potent antifungal activity at comparatively low concentration. Based on the present findings, it is concluded that silver nanoparticles could be used as an antifungal agent in controlling various plant diseases caused by fungi. However, it necessitates further study to understand exact mechanism by which silver nanoparticles enter into the fungal cell wall.

\section{References}

1. Sidana J, Saini V, Dahiya S, Nain P, Bala S (2013) A Review on Citrus "The Boon of Nature". Int J Pharm Sci 18(2): 20-27.

2. Embaby EM, Hazaa M, Laila Hagag F, Talaat El-Sayed I, Faten S AbdelAzem (2013) Decay of some citrus fruit quality caused by fungi and their Control: III- Control Blue and Green mould decay by using some alternative fungicides. J Appl Sci Res 9(8): 5086-5096.

3. Ammar MI, El-Naggar MA (2014) Screening and Characterization of Fungi and their associated Mycotoxins in some Fruit Crops. International Journal of Advanced Research 2(4): 1216-1227.

4. Embaby EM, Hazaa M, Laila Hagag F, Talaat El-Sayed I, Faten S AbdelAzem (2013) Decay of some citrus fruit quality caused by fungi and their Control: II- Control Alternaria rot or core rot decay by using some alternative fungicides. J Appl Sci Res 9(11): 5671-5678.

5. Morones JR, Elechiguerra JL, Camacho A, Holt K, Kouri JB, et al. (2005) The bactericidal effect of silver nanoparticles. Nanobiotechnol 16(10): 2346-2353.
6. Norman S, Hongda C (2013) IB in depth. Special section on nanobiotechnology Part 2. Ind Biotechnol 9(1): 17-18.

7. Nikunj P, Purvi D, Niti P, Anamika J, Hemant K Gautam (2014) Agronanotechnology for plant fungal disease management: A Review. Int J Curr Microbiol App Sci 3(10): 71-84.

8. Kim SW, Jung JH, Lamsal K, Kim YS, Min JS, et al. (2012) Antifungal effects of silver nanoparticles (AgNPs) against various plant pathogenic fungi. Mycobiology 40(1): 53-58.

9. El Mahdy MM, Eldin TA, Aly HS, Mohammed FF, Shaalan MI (2014) Evaluation of hepatotoxic and genotoxic potential of silver nanoparticles in albino rats. Exp Toxicol Pathol 67(1): 21-29.

10. Salaheldin TA, Husseiny SM, Al-Enizi AM, Elzatahry A, Cowley AH (2016) Evaluation of the cytotoxic behavior of fungal extracellular synthesized Ag nanoparticles using confocal laser scanning microscope. Int J Mol Sci 17(3): 329.

11. Bukar A, Mukhtar MD, Adamu S (2009) Isolation and identification of postharvest spoilage fungi associated with sweet oranges (citrus sinensis) traded in Kano metropolis. Bayero Journal of Pure and Applied Sciences 2(1): 122-124.

12. Parey MA, Razdan VK, Sofi TA (2013) Comparative study of different fungi associated with fruit rot of chilli and screening of chilli germplasm against Colletotrichum capsici. International Journal of Agricultural Crop Sciences 5(7): 723-730.

13. Barnett HL, Hunter BB (1972) Illustrated genera of imperfect fungi. ( $3^{\text {rd }}$ edn), Burgess Publishing Co., pp. 273.

14. Francis MI, Pena A, Graham JH (2010) Detached leaf inoculation of germplasm for rapid screening of resistance to citrus canker and citrus bacterial spot. European Journal of Plant Pathology, 127(4): 571-578.

15. Lamsal K, Kim SW, Jung JH, Kim YS, Kim KS, et al. (2011) Application of silver nanoparticles for the control of colletotrichum Species In vitro 
and pepper anthracnose disease in field. Mycobiology 39(3): 194-199.

16. Gomez KA, Gomez AA (1984) Statistical procedures for agricultural research. ( $2^{\text {nd }}$ edn) John Wiley \& Sons, USA, pp. 680.

17. Youssef KYA, Mustafa ZMM, Gehan Mounir A, Abo Rehab MEA (2015) Preliminary studies on fungal species associated with guava fruit drop disease and possible management. Egypt J Phytopathol 43(1).

18. Youssef K, Sanzani SM, Ligorio A, Ippolito A, Terry LA (2014) Sodium carbonate and bicarbonate treatments induce resistance to postharvest green mold on citrus fruit. Postharvest Biology and Technology 87: 61-69.

19. Moscoso-Ramírez PA, Montesinos-Herrero C, Palou L (2013) Control of citrus postharvest Penicillium molds with sodium ethylparaben. Crop Prot 46: 44-51.

20. Youssef K, Ligorio A, Sanzani SM, Nigro F, Ippolito A (2011) Investigations on Penicillium spp. population dynamics packinghouses. J Plant Pathol 93(4): 61-62.

21. Brown GE, Eckert JW (2000) Alternaria rot. In: Timmer LW, et al. (Eds.), Compendium of Citrus Diseases ( $2^{\text {nd }}$ edn) APS Press, St. Paul, MN, USA, pp. 128.

22. Barry P, Mike M, Patricia F (2003) This is a part of 2003 Citrus Research Report. The University of Arizona College of Agriculture and Life Sciences.
23. Peever TL, Carpenter-Boggs L, Timmer LW, Carris LM, Bhatia A (2005) Citrus black rot is caused by phylogenetically distinct lineages of Alternaria alternata. Phytopathology 95(5): 512-518.

24. Milind SL (2008) Citrus fruit biology, technology and evaluation. (1 $1^{\text {st }}$ edn) Academic Press is an Imprint of Elsevier, USA.

25. Shideh M, Naser S (2012) Phylogenetic analysis of Alternaria species associated with citrus black rot in Iran. Plant Pathology \& Microbiology 3: $1-7$.

26. Sanzani SM, Schena L, De Cicco V, Ippolito A (2012) Detection and quantification of Botrytis cinerea in symptomless table grape stamens and berries. Postharvest Biol Technol 68: 64-71.

27. Youssef K, Ligorio A, Nigro F, Ippolito A (2012) Activity of salts incorporated in wax in controlling postharvest diseases of citrus fruit. Postharvest Biol Technol 65: 39-43.

28. Youssef K, Ligorio A, Sanzani SM, Nigro F, Ippolito A (2012) Control of storage diseases of citrus by pre- and postharvest application of salts. Postharvest Biol Technol 72: 57-63.

29. Krishnaraj C, Ramachandran R, Mohan K, Kalaichelvan PT (2012) Optimization for Rapid Synthesis of Silver Nanoparticles and Its Effect on Phytopathogenic Fungi. Spectrochimica Acta Part A 93: 95-99. 